\title{
Neumoparotiditis o neumoparótida en el niño: Un diagnóstico diferencial a considerar
}

\author{
Karla Moënne B., Jaime Cordero T. y Cecilia Poli H.
}

\section{Pneumoparotitis or pneumoparotid: A differential diagnosis to consider}

Childhood parotid swelling has a number of differential diagnosis mostly of inflammatory origin. Pneumoparotitis is an uncommon cause of parotid inflammation. It is caused by an excessive increase of intraoral pressure and secondary passage of air into the Stensen or Stenon duct and its glandular branches. Diagnostic clues can usually be obtained by a directed anamnesis. Ultrasonography (US) and computed tomography are essential diagnostic tools for this condition that has a benign course with spontaneous resolution in most cases. We present four cases of pneumoparotitis diagnosed by US in children 5 to 13 years of age. One of the cases occurred after the child chewed gum and made bubbles for a prolonged timeperiod and the other three after inflating baloons, making bubbles inside a pool and after playing the flute. All cases resolved spontaneously after two days. We suggest to consider pneumoparotitis in the differential diagnosis of parotid swellig in children.

Key words: Pneumoparotitis, pneumparotid, ultrasonography, children

Palabras clave: Neumoparotiditis, neumoparótida, ultrasonografía, niños.

\section{Introducción}

$\mathrm{E}$ n el niño, las glándulas parótidas no son palpables en condiciones normales, por lo que su aumento de volumen uni o bilateral sugiere la presencia de patología.

Existen numerosas causas de aumento de volumen parotídeo, entre las cuales las alteraciones inflamatorias son las más frecuentes; las masas se observan muy ocasionalmente en la práctica pediátrica.

En el diagnóstico diferencial de la inflamación parotídea se incluyen etiologías infecciosas (virales y bacterianas), auto-inmunes (síndrome de Sjögren, vasculitis de Wegener), alteraciones endocrinas (diabetes mellitus, enfermedad de Cushing, hipotiroidismo), falla hepática, enfermedades granulomatosas (sarcoidosis), reacciones alérgicas o reacciones adversas a fármacos, trauma y obstrucción ductal $^{1}$ (Tabla 1).

La neumoparotiditis o neumoparótida es una entidad poco frecuente, que resulta del aumento de presión intra-oral y paso de aire al conducto de Stensen (también denominado Stenon*), que debe ser considerada en el diagnóstico diferencial del aumento de volumen parotídeo cuando existan antecedentes sugerentes ${ }^{2}$. Ha sido denominada también como: neuma-sialoadenitis, wind parotitis, pneumatocele glandulae parotis y parotiditidis anestésico-quirúrgica ${ }^{2,3}$. Algunos autores consideran más apropiado el término neumoparótida, que describe la presencia de aire en la parótida, aun en ausencia de inflamación demostrable ${ }^{1}$.

Nuestro objetivo es presentar cuatro casos pediátricos de neumoparotiditis o neumoparótida, con el propósito de dar a conocer esta patología e incorporarla en el diagnóstico diferencial de niños con aumento de volumen uni o bilateral de glándulas parótidas.

\section{Casos clínicos}

Caso 1. Varón de 13 años, que consultó a su pediatra por aumento de volumen parotídeo derecho de aparición brusca y aproximadamente tres horas de evolución, sensible a la palpación. La madre refería como antecedente un episodio de aumento de volumen parotídeo derecho a los seis años de edad, con resolución espontánea. El paciente había recibido un esquema de vacunación completo.

Se realizó ultrasonografía (US) utilizando transductor de alta resolución demostrándose una glándula parótida derecha francamente aumentada de tamaño, y ecogenicidad, con linfonodos de hasta 8,9 x 7,6 mm en su interior (Figuras 1a,1b). En el espesor del parénquima parotídeo llamó la atención presencia de imágenes lineales ecogé-
Clínica Las Condes, Santiago, Chile

Departamento de Radiología (KMB) Departamento de Pediatría (JCT) Universidad de Chile, Santiago

Facultad de Medicina, Escuela de Postgrado (CPH)

Recibido: 29 de abril de 2009 Aceptado: 2 de octubre de 2009

Correspondencia a: Karla Moënne Bulhmann. kmoenne@clc.cl

*Nota al respecto en página 559. 


\section{Tabla 1. Causas de inflamación de las glándulas salivales}

Inflamatorias específicas

- Agudas

- Viral (parotídeo, Coxsackie A, ECHO y coriomeningitis linfocitaria)

- Bacteriana (estafilocóccica, estreptocóccica, neumocóccica, por bacilos gramnegativos)

- Crónicas (tuberculosis, actinomicosis, sarcoidosis)

- Recurrente subaguda o crónica (autolimitada, progresiva, lesión linfoepitelial y síndrome de Sjögren)

Sistémicas y secundarias a desórdenes metabólicos

- Obesidad, hipertensión arterial, diabetes mellitus, malnutrición y deficiencias asociadas, alcoholismo y hepatitis alcohólica

Hipersensibilidad a fármacos

Alteraciones glandulares locales

- Sialolitiasis, sialoangiectasia, trauma, cuerpo extraño, fístula, linfadenopatías parotídeas, actínica

Quiste de extravasación y retención

- Mucocele, ránula

Obstrucciones ductales locales

- Congénitas, tapones mucosos

Misceláneas

- Neumoparotiditis

- Psicogénicas
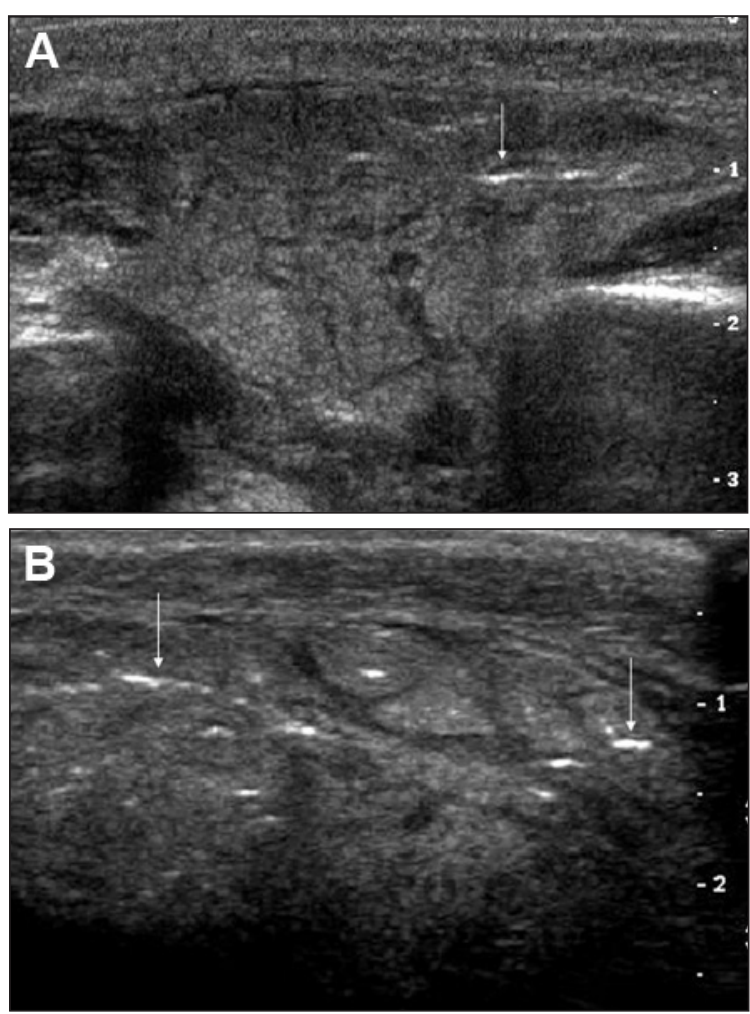

nicas con aspecto de corresponder a aire, que también se demostraron en toda la extensión del conducto de Stensen, hasta su desembocadura en la cavidad oral (Figura 1c). Al complementar con Doppler color, se observaba un aumento discreto de la vascularización de la glándula parótida. La parótida izquierda aparecía ligeramente prominente, sin evidencias de tractos aéreos en el momento del examen.

A raíz de los hallazgos del ultrasonido, la anamnesis dirigida reveló que el día anterior el niño había estado masticando chicle y haciendo globos en forma repetida durante muchas horas.

El paciente se manejó con analgesia, observándose la resolución clínica espontánea del cuadro a los dos días. La US de control efectuada a los cuatro días resultó normal.

Controlado hasta la fecha, durante tres años, el niño no ha vuelto a presentar episodios similares.

Caso 2. Varón de 10 años y 9 meses que consultó en el Servicio de Urgencia por dolor y discreto aumento de volumen de la mejilla derecha, por lo que se solicitó US de tejidos blandos faciales y cervicales.

El examen de ultrasonido demostró presencia de pequeña cantidad de aire en los conductos intraglandulares, en ambas parótidas, sin otras alteraciones asociadas (Figura 2).

La anamnesis dirigida, efectuada después de la US, reveló que los días previos el niño había participado en la semana del colegio e inflado gran cantidad de globos.

Se le indicó analgésicos según necesidad y el paciente

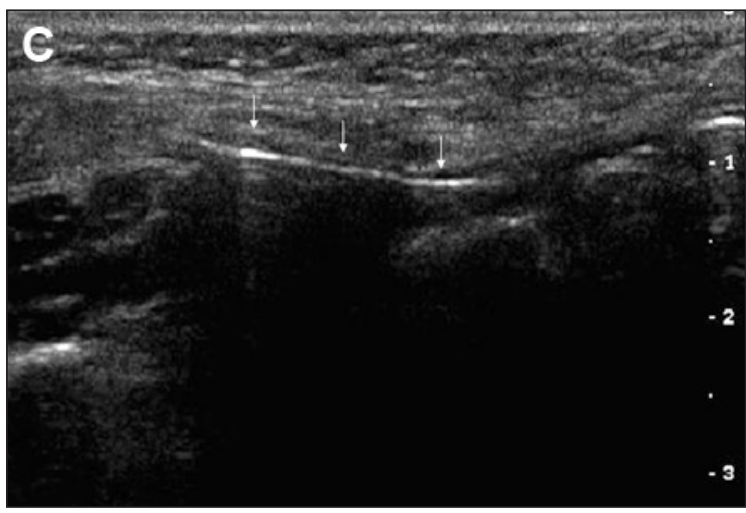

Figura 1. Caso $N^{\circ} 1 \mathrm{a}, \mathrm{b}$ : El ultrasonido demuestra aumento de volumen y ecogenicidad de la parótida derecha, con imágenes lineales ecogénicas que corresponden a aire (flechas); en el trayecto del conducto de Stensen derecho también se observa aire (flechas) (c).

evolucionó favorablemente con desaparición de los síntomas en el curso de dos días. No se efectuó control de US.

Caso 3. Niña de 5 años y 2 meses que acudió al Servicio de Urgencia por dolor y leve aumento de volumen pre-auricular izquierdo. Al examen impresionaba como un aumento de volumen parotídeo, sensible. Una US demostró un aumento de volumen y ecogenicidad que comprometía parcialmente la glándula parótida izquierda, en el espesor de la cual se constató un par de imágenes ecogénicas con aspecto de aire (Figura 3). 


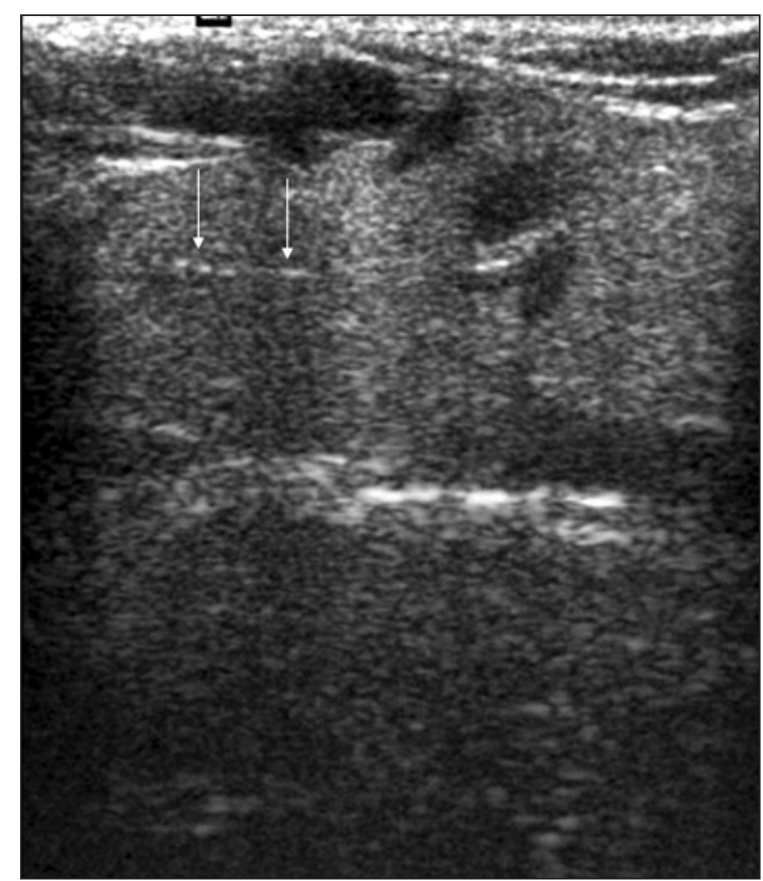

Figura 2. Caso $N^{\circ} 2$ : El ultrasonido demuestra pequeña cantidad de aire (flechas) en algunos canalículos parotídeos izquierdos; en tiempo real durante el examen, se observó que éste se movilizaba en el interior de los pequeños conductos.

Con posterioridad a los hallazgos ecográficos, la anamnesis dirigida reveló que durante varias horas, la tarde anterior, la paciente había permanecido sumergiéndose repetidamente en la piscina para hacer "burbujas", para lo cual guardaba el aire en la cavidad oral antes de meterse al agua. Su evolución fue favorable.

Caso 4. Niña de 9 años 4 meses, que consultó en el Servicio de Urgencia por dolor y aumento de volumen en la parótida derecha, que se comprobó al examen clínico. La US demostró el aumento de volumen de la parótida derecha, con áreas focales de aumento de ecogenicidad. En el espesor de la glándula se constató un trayecto lineal ecogénico sugerente de corresponder a aire (Figura 4).

La anamnesis dirigida en esta paciente aportó el antecedente que los últimos dos días la niña había estado soplando una flauta "dura" de madera, que le habían traído desde un país vecino. Evolucionó con rápida regresión de los síntomas.

\section{Discusión}

La neumoparotiditis o neumoparótida fue descrita por primera vez por Hyrtl en 1865, en sopladores de vidrio $^{1}$. La entrada de aire a la glándula parótida ocurre

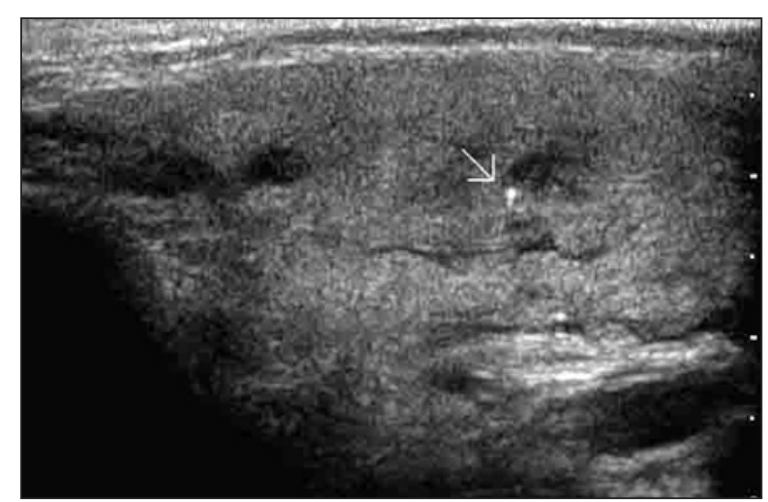

Figura 3. Caso $\mathrm{N}^{\circ}$ 3: $\mathrm{El}$ ultrasonido demuestra áreas de aumento de ecogenicidad del parénquima parotídeo e imagen ecogénica puntiforme que corresponde a aire (flecha).

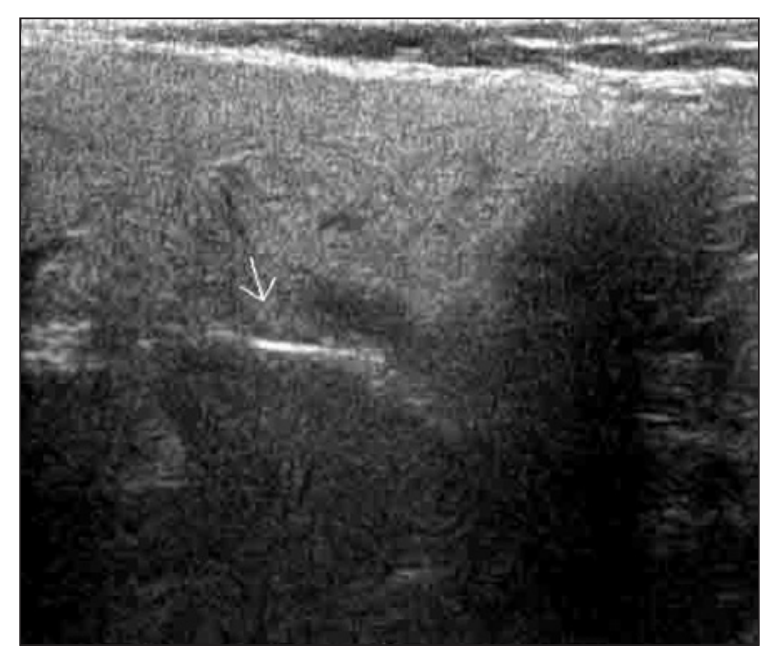

como resultado de un aumento de presión en la cavidad oral, que es seguida de paso aire al conducto de Stensen y sus ramas, produciendo inflamación uni o bilateral del parénquima de la glándula.

Factores de riesgo. La entrada de aire puede ocurrir como evento aislado o en forma recurrente. Se han descrito neumoparótidas transitorias posteriores a procedimientos dentales en que se utilizan instrumentos que funcionan con aire comprimido, que puede aumentar la presión hasta $60 \mathrm{mmHg}^{3}$, en la extubación de pacientes anestesiados al toser contra una presión positiva, al inflar globos, al "sonarse" en forma agresiva o con posterioridad a una descompresión rápida en el buceo (Tabla 2$)^{4}$. Puede presentarse como parotiditis recurrente en pacientes con tos crónica (EPOC, fibrosis quística) $)^{5,2}$ que aumentan la presión intraoral en un intento por suprimir la tos, o como un accidente ocupacional en sopladores de vidrio, trompetistas y buceadores. Algunos pacientes, especialmente niños y adolescentes, realizan maniobras con las cuales pueden auto-inducir una neumoparotiditis o neu-
Figura 4. Caso $N^{\circ} 4$ : El ultrasonido demuestra aumento de ecogenicidad de la parótida derecha con tracto lineal ecogénico en su espesor que corresponde a aire (flecha). 
Tabla 2. Eventos asociados a neumoparotiditis transitoria

Procedimientos dentales con instrumental de aire comprimido

Presión positiva durante la extubación post anestesia

Inflar globos

Sonarse en forma agresiva

Descompresión rápida en buceadores

moparótida a través de hábitos que aumentan la presión intra-oral (tics), en enfermedades psicosomáticas, como un mecanismo evitativo ante fobia escolar o, tan sólo para llamar la atención u obtener ganancias secundarias ${ }^{6,7}$.

Fisiopatología. La presión intraoral normal es de 2-3 $\mathrm{mmHg}$ y al tocar una trompeta, por ejemplo, puede ascender hasta $140-150 \mathrm{mmHg}^{1}$. Los conductos parotídeos son más estrechos a nivel del ostium donde poseen una mucosa redundante que evita en forma natural la entrada de aire ${ }^{8}$. Al distender las mejillas, esta redundancia mucosa sella el orificio y aumenta la angulación del conducto que es entonces comprimido por el músculo buccinador, alcanzando un diámetro máximo de $1,2 \mathrm{~mm}^{7,9}$. Se ha descrito reacción inflamatoria en el parénquima glandular, con niveles elevados de amilasas en sangre; probablemente la disección que causa el aire en los acinos puede producir esta liberación de amilasas ${ }^{10}$. En algunos casos, puede haber entrada de aire en relación a parótidas con alteraciones anatómicas subyacentes, con conductos dilatados, hipertrofia del músculo masétero o debilidad del buccinador en que aumentos de la presión intra-oral sobrepasan los mecanismos protectores ${ }^{7}$. Han describió el caso de un adolescente de 13 años con más de 20 episodios de neumoparotiditis en que la anatomía patológica mostró conductos de $2,3 \mathrm{~mm}^{7}$. Se ha descrito también que la oclusión transitoria, por mucus, de una glándula parótida normal puede generar un círculo vicioso de dilatación, incompetencia ductal, con entrada de aire y saliva en el conducto ${ }^{7}$. Esta injuria recurrente podría romper los acinos, permitiendo que el aire se extienda hacia la cápsula y produzca una dehiscencia a nivel del ángulo posterior de la mandíbula y el espacio parafaríngeo, ocasionando enfisema subcutáneo. Cuando se compromete el espacio retro-faríngeo, existe riesgo de neumomediastino y neumotórax ${ }^{10,11}$. Clínicamente, si el enfisema subcutáneo es muy prominente, se debe explorar el tórax en busca de neumomediastino.

Diagnóstico. El motivo de consulta suele ser el aumento de volumen de la región parotídea; la historia clínica y el examen físico son claves en el diagnóstico. La anamnesis dirigida y cuidadosa puede develar el evento responsable de la inflamación parotídea (Tabla 2). Habitualmente los pacientes refieren dolor, a veces eritema, e hipersensibilidad variable de la región parotídea, sin fiebre asociada. Al examen físico se puede encontrar enfisema subcutáneo, que puede extenderse hacia el cuello, crepitación a lo largo del conducto de Stensen y, salivación espumosa al comprimir la glándula. La neumoparotiditis o neumoparótida autoinducida es característicamente más difícil de diagnosticar, ya que habitualmente los pacientes ocultan el antecedente o no asocian las maniobras con la insuflación parotídea y consecuente inflamación; en la historia de algunos pacientes destacan numerosos episodios de parotiditis uni o bilaterales, sin evidencias de sialolitiasis ${ }^{1,6}$.

Diversos exámenes de imágenes permiten demostrar el aire en los conductos de Stensen e intraglandulares, además de grados variables de compromiso inflamatorio de la glándula. Si bien la tomografía computada (TC) es el método de imagen más utilizado en los reportes existentes en la literatura ${ }^{1,4,10,12}$, la US también permite demostrar las alteraciones ${ }^{12}$, como sucedió en nuestros pacientes, por lo que aparece recomendable como examen inicial en los pacientes pediátricos.

La radiografía se ha descrito en el estudio diagnóstico, aunque puede resultar normal. Es posible visualizar aire en el conducto de Stensen o en la glándula parótida, e incluso enfisema subcutáneo, en casos graves. La sialografía, cuyo uso ha disminuido significativamente en la última década, puede resultar: normal, mostrar conductos dilatados o, evidenciar imágenes radio-lúcidas en los conductos contrastados, que corresponden a aire en su interior ${ }^{12}$.

Como es sabido, la US es un examen inocuo, rápido de efectuar, de bajo costo y que está disponible en la mayoría de los centros de atención en salud. Presenta un alto rendimiento en el estudio de las glándulas parótidas ${ }^{13,14}$ y resulta útil, tanto en el diagnóstico como en el seguimiento de esta patología. Permite estudiar el parénquima glandular y visualizar imágenes ecogénicas lineales que corresponden a aire, a veces con artefacto de reverberación y que pueden movilizarse durante la observación, ya sea en los conductos o en el tejido glandular. La TC también es útil en el diagnóstico, logrando detectar pequeñas cantidades de aire, tanto en la glándula como a nivel ductal ${ }^{12}$; en los pacientes pediátricos su uso es más restringido por la exposición a radiación ionizante. Existen algunos reportes de utilización de sialografía por resonancia magnética en el estudio de estos pacientes ${ }^{15}$.

Tratamiento. El tratamiento de la neumoparotiditis o neumoparótida depende esencialmente de la causa. Un episodio aislado requiere sólo tranquilizar a los padres y al niño, ya que la inflamación suele resolverse en 
forma espontánea en uno o dos días, requiriendo a veces analgésicos. En la literatura se menciona la profilaxis con antimicrobianos orales, sin claros fundamentos ${ }^{1,7,13,15}$.

En el caso de la neumoparotiditis ocupacional, el paciente puede utilizar técnicas para reducir la probabilidad de insuflación parotídea. Los casos graves o recurrentes, que a veces se asocian a infección y neumomediastino, pueden requerir de intervención quirúrgica: resecciones glandulares, reubicación o ligadura del conducto de Stensen o parotidectomía parcial con ligadura de conductos ${ }^{8}$. En los pacientes con neumoparotiditis o neumoparótida autoinducida se debe incluir psicoterapia para corregir el trastorno adaptativo subyacente ${ }^{16,17}$.

\section{Conclusiones}

La neumoparotiditis o neumoparótida debe considerarse en el diagnóstico diferencial del aumento de volumen parotídeo en la edad pediátrica, efectuando una anamnesis dirigida.

La US constituye una herramienta de gran utilidad en el estudio diagnóstico y seguimiento de estos pacientes.

\section{Resumen}

En el niño, el aumento de volumen parotideo plantea diversas posibilidades diagnósticas, siendo la etiología inflamatoria la más frecuente. La neumoparotiditis (o neumoparótida) es una alteración inflamatoria poco frecuente, causada por aumento de presión intra-oral y paso secundario de aire al conducto de Stensen o Stenon y a ramas intraglandulares. Al investigar dirigidamente, es posible obtener antecedentes sugerentes de esta entidad. La ultrasonografía y la tomografía axial computada son herramientas diagnósticas útiles en estos pacientes. La evolución de este cuadro es benigna y autolimitada. Se presentan cuatro casos de neumoparotiditis, diagnosticados mediante ultrasonografía; corresponden a niños (5 -13 años), en cuyos antecedentes destaca: haber masticado chicle el día anterior haciendo globos en forma repetida, haber inflado globos, hecho "burbujas" bajo el agua y, soplado flauta en forma prolongada. En todos, la evolución fue favorable, desapareciendo las alteraciones en dos días. Estimamos recomendable considerar la neumoparotiditis en el diagnóstico diferencial del aumento de volumen parotídeo en niños.

\section{Referencias}

1.- Luaces R, Ferreras J, Patiño B, Garcia-Rozado A, Vázquez I, López-Cedrún J L. Pneumoparotid: a case report and review of the literatura. J Oral Maxilofac Surg. 2008; 66 (2): 362-5.

2.- Huang P C, Schuster D, Misko G. Pneumoparotid: a case report and review of its pathogenesis, diagnosis and management. Ear Nose Throat J 2000; 79 (4): 316-7.

3.- Piette E, Walker R T. Pneumoparotid during dental treatment. Oral Surg Oral Med Oral Pathol 1991; 72 (4): 415-7.

4.- Reilly D J. Benign transient swelling of the parotid glands following general anesthesia: "Anesthesia mumps". Anesth Analg 1970; 49: 560-3.

5.- Cook J N, Layton S A. Bilateral parotid swelling associated with chronic obstructive pulmonary disease: A case of pneumoparotid. Oral Surg Oral Med Oral Pathol 1993; 76: 157-8.

6.- Martín-Granizo R, Herrera M, García-González
D, Mas A. Pneumoparotid in childhood:Report of two cases. Oral Maxillofac Surg 1999; 57 (12): 1468-71.

7.- Han S, Isaacson G. Recurrent Pneumoparotid: Cause and Treatment. Otolaryngol Head Neck Surg 2004; 131: 758-61.

8.- Richards A T, Digges N, Norton N S, Quinn T $\mathrm{H}$, Say P, Galer, et al. Surgical anatomy of the parotid duct with emphasis on the major tributaries forming the duct and the relationship of the nerve to the duct. Clin Anat 2004; 17 (6): 463-7.

9.- Zenk J, Zilarsky B, Hosemann W G. The diameters of Stenson's and Warthon's ducts and their importance in diagnosis and therapy. HNO 1998; 46 (12): 980-5.

10.- Balasubramanian S, Srinivas S, Aparna K. Pneumoparotitis with subcutaneous emphysema. Indian Pediatrics 2008; 45: 58-60.

11.- Kirsch C, Shinn J, Porzio R. Pneumoparotid due to spirometry. Chest 1999; 116: 1475-8.

12.- Maehara M, Ikeda K, Ohmura N, Sugimoto T,
Harima K, Ino C, et al. Multislice computed tomography of pneumoparotid: a case report. Radiat Med 2005; 23 (2): 147-50.

13.- García C, Flores P, Arce J D, Chuaqui B, Schwartz D. Ultrasonography in the study of salivary gland lesions in children. Pediatr Radiol 1998; 28: 418-25.

14.- Nazar G, Iñiguez F, Der C, Méndez C, García C, Arce J D, Díaz V, Talesnik E. Parotiditis aguda recurrente en el niño. Rev Chil Pediatr 2001; 72: 437-42.

15.- Sittel C, Jungen M. High-resolution magnetic resonance imaging of recurrent pneumoparotitis. Ann Otol Rhinol Laryngol 1999; 108 (8): 816-8.

16.- Prabhu S, Tran B. Pneumoparotitis. Pediatr Radiol 2008; 38: 1144.

17.- Faure F, Plouin Gaudon I, Tavernier L, Ayari S, Folia M. A rare presentation of recurrent parotid swelling: Self-induced parotitis. International Journal of Pediatric Otholaryngology Extra 2009; 4: 29-31.

\section{¿Stenon o Stensen?}

El Dorland's, célebre diccionario, dice la increíble verdad: "Blasius Duct or Stensen's duct or Steno's Duch. Finalmente atribuye la primacía al médico danés Niels Stensen (Nicolaus Steno), quien fuera anatomista en Italia y viviera entre 1638 y 1686. Luego, "Steno" es la forma latina de escribir "Stensen". Los sabios del siglo XVII solían latinizar sus nombres... Pero él se puso Steno y no Stenon. Los anglosajones hablan siempre de Stensen's Duct, nunca de Stenon.

Walter Ledermann $D$. Laboratorio de Microbiología, Hospital Luis Calvo Mackenna Santiago, Chile 